\title{
Phospholipase D activates HIF-1-VEGF pathway via phosphatidic acid
}

\author{
Songyi Han ${ }^{1,3}$, Jeongsoon Huh ${ }^{1,3}$, Wooseong $\mathrm{Kim}^{1}$, Seongkeun Jeong ${ }^{1}$, Do Sik Min ${ }^{2}$ and Yunjin Jung ${ }^{1}$
}

Growth factor-stimulated phospholipase D (PLD) catalyzes the hydrolysis of phosphatidylcholine (PC), generating phosphatidic acid (PA) which may act as a second messenger during cell proliferation and survival. Therefore, PLD is believed to play an important role in tumorigenesis. In this study, a potential mechanism for PLD-mediated tumorigenesis was explored. Ectopic expression of PLD1 or PLD2 in human glioma U87 cells increased the expression of hypoxia-inducible factor-1 $\alpha$ (HIF-1 $\alpha$ ) protein. PLD-induced HIF-1 activation led to the secretion of vascular endothelial growth factor (VEGF), a HIF-1 target gene involved in tumorigenesis. PLD induction of HIF-1 $\alpha$ was significantly attenuated by 1 -butanol which blocks PA production by PLD, and PA per se was able to elevate HIF-1 $\alpha$ protein level. Inhibition of mTOR, a PA-responsive kinase, reduced the levels of HIF-1 $\alpha$ and VEGF in PLD-overexpressed cells. Epidermal growth factor activated PLD and increased the levels of HIF-1 $\alpha$ and VEGF in U87 cells. A specific PLD inhibitor abolished expression of HIF-1 $\alpha$ and secretion of VEGF. PLD may utilize HIF-1-VEGF pathway for PLD-mediated tumor cell proliferation and survival.

Experimental \& Molecular Medicine (2014) 46, e126; doi:10.1038/emm.2014.86; published online 19 December 2014

\section{INTRODUCTION}

Phospholipase D (PLD) generates phosphatidic acid (PA) and choline by hydrolyzing phosphatidylcholine (PC) in response to a variety of stimuli. ${ }^{1,2}$ Two major isoforms of PC-specific PLD have been identified in mammals, namely PLD1 and PLD2. PLD promotes proliferation and suppresses apoptosis in many cancer cells, which is an important aspect of tumorigenesis. ${ }^{3,4} \mathrm{PA}$, the metabolic product of PLD, acts as a mediator to transmit the mitogenic/oncogenic signals to downstream signaling molecules including $\mathrm{mTOR}^{5-7}$ In line with these findings, PLD activity has been reported to be elevated in a large number of human cancers. ${ }^{4,8,9}$

Hypoxia-inducible factor- $1 \alpha$ (HIF-1) is a heterodimeric transcription factor composed of the basic helix-loop-helixPAS domain, containing HIF- $1 \alpha$ and arylhydrocarbon receptor nuclear translocator (HIF-1 $\beta$ ). The activity of HIF-1 is determined primarily by HIF- $1 \alpha$, which is regulated at the protein level in an oxygen-sensitive manner, in contrast to HIF-1 $\beta$, which is stably expressed. During normoxia, HIF- $1 \alpha$ is efficiently degraded through the VHL-dependent ubiquitin-proteasome pathway. Under hypoxia, HIF-1 $\alpha$ protein is markedly stabilized, translocates to the nucleus, heterodimerizes with HIF-1 $\beta$ and activates an array of genes that enhance cellular adaptation to hypoxia. ${ }^{10,11}$

The role of HIF- $1 \alpha$ is under increasing scrutiny by cancer researchers. HIF-1 activates the transcription of many genes controlling glycolysis, growth factors, erythropoiesis, ${ }^{12}$ heme metabolism, ${ }^{13}$ iron transport, vasomotor regulation and nitric oxide synthesis, ${ }^{14}$ and, thus, may influence the survival, proliferation and metastasis of tumor cells. Especially, by activating the transcription of vascular endothelial growth factor (VEGF) gene, HIF-1 is considered a central initiator of angiogenic activity in tumors. ${ }^{15}$ Interestingly, a number of stimuli including growth factors and oncogenic activation which enhance PLD activity are able to induce HIF- $1 \alpha$ protein and both HIF-1 and PLD play an important role in tumorigenesis. ${ }^{16,17}$ However, there has been no prior study on the relevance of HIF-1 to PLD-mediated oncogenesis. Here, we show that PLD induces HIF-1 $\alpha$ via PA, the metabolic product of PLD, and HIF-1 $\alpha$ is partly responsible for PLDmediated VEGF secretion. As VEGF is among the most potent angiogenic factors and is required for the growth of most tumors, HIF-1-induced VEGF may act as a downstream effector for PLD-dependent tumorigenesis.

\footnotetext{
${ }^{1}$ College of Pharmacy, Pusan National University, Busan, Republic of Korea and ${ }^{2}$ Department of Molecular Biology, College of Natural Science, Pusan National University, Busan, Republic of Korea

${ }^{3}$ These authors contributed equally to this work.

Correspondence: Dr DS Min, Department of Molecular Biology, College of Natural Science, Pusan National University, Busandaehak-ro 63beon-gil, Geumjeong-gu, Busan 609-735, Republic of Korea.

E-mail: minds@pusan.ac.kr

or Professor Y Jung, College of Pharmacy, Pusan National University, Busandaehak-ro 63beon-gil, Geumjeong-gu, Busan 609-735, Republic of Korea. E-mail: jungy@pusan.ac.kr

Received 10 September 2014; revised 2 October 2014; accepted 6 October 2014
} 


\section{MATERIALS AND METHODS}

\section{Chemicals}

1, 2-Dioctanoyl-sn-glycerol 3-phosphate sodium salt (cell-permeable PA), echinomycin (NSC-13502), rapamycin, 1-butanol, 2-butanol, sodium 2-ketoglutarate, sodium ascorbate, ferrous chloride and 1,10phenanthroline monohydrate were purchased from Sigma Chemical Co. (St Louis, MO, USA). HIF prolyl hydroxylase (HPH)-2 plasmid was kindly provided by S. McKnight (University of Texas Medical Center, Dallas, TX, USA). 5-Fluoro-2-indolyl des-chlorohalopemide (pan-PLD inhibitor, FIPI) was purchased from Cayman Chemical (Ann Arbor, MI, USA). Recombinant human epidermal growth factor (EGF) was purchased from R\&D systems (Minneapolis, MN, USA).

\section{Cell culture and transient transfection}

Human glioma U87 cells stably transfected with PLD1, PLD2 or empty vector ${ }^{18}$ and VHL-deficient human renal carcinoma cells (UMRC) and UMRC stably transfected with VHL (UMRC/VHL) (a gift from Dr Isaacs JS, The Medical University of South Carolina) were grown in Dulbecco's Modified Eagle's medium (Hyclone, South Logan, UT, USA) supplemented with $10 \%$ fetal bovine serum (Hyclone) and penicillin/streptomycin (Hyclone). For transient transfection of plasmids, cells were plated in 6-well plates to be $50-60 \%$ confluent on the day of transfection with a HIF-responsive luciferase reporter plasmid $(0.4 \mu \mathrm{g}$, a gift from Dr G Melillo, NCI) and CMV Renilla luciferase plasmid (4 ng, Promega, Madison, WI, USA). Fugene (Roche, Indianapolis, IN, USA) was used as a transfection reagent. One day post transfection, cells were lysed with passive lysis buffer. The luciferase activities were measured using a dual luciferase kit (Promega). For transfection of a siRNA, chemically synthesized double-stranded siRNA specific for HIF-1 $\alpha$ (HIF-1 $\alpha$ siRNA) 5-AGA GGUGGAUAUGUGUGGGdTdT-3 and 5-CCCACACAUAUCCAC CUCUdTdT-3 were purchased from Dharmacon Research, Inc (Dharmacon, Chicago, IL, USA). The siRNA was transfected $\left(200 \mathrm{nmoll}^{-1}\right)$ using a Dharmafect transfection reagent (Dharmacon Research) according to the manufacturer's instructions. A predesigned nontargeting siRNA sequence (Dharmacon Research) was used as a nonspecific control.

\section{Immunoblot analysis}

Cells were lysed and nuclear or whole cell extracts were prepared as described previously. ${ }^{19}$ Protein concentration in the supernatants was determined by the BCA method. The cellular extracts were electrophoretically separated using 7.5 or $10 \%$ sodium dodecyl sulfatepolyacrylamide gel electrophoresis gels. Proteins were transferred to nitrocellulose membranes (Protran, Schleicher \& Schuell, Keene, NH, USA) and HIF- $1 \alpha$ protein was detected in nuclear extracts $(30-40 \mu \mathrm{g})$ or in whole cell lysates $(50-70 \mu \mathrm{g})$ using a monoclonal anti-HIF-1 $\alpha$ antibody purchased from BD Biosciences Pharmingen (San Jose, CA, USA). Donkey anti-mouse secondary antibody (Santa Cruz Biotechnology, Santa Cruz, CA, USA) was used at a dilution of 1:2000. PLD1 and 2 proteins were detected in whole cell extracts $(30-40 \mu \mathrm{g})$ using anti-PLD antibody. ${ }^{18}$ Goat anti-rabbit secondary antibody (KPL protein research products, Gaithersburg, MD, USA) was used at a dilution of 1:5000. Signals were visualized using the SuperSignal chemiluminescence substrate (Pierce, Rockford, IL, USA). Experiments were performed in duplicate and normalized with antibodies to topoisomerase II (Santa Cruz Biotechnology) for nuclear HIF-1 $\alpha$ and to $\beta$-tubulin (Santa Cruz Biotechnology) for PLD and HIF-1 $\alpha$ in whole cell lysate.

\section{RNA isolation and Q-PCR}

Total RNA was isolated by the TRIzol reagent (Invitrogen, Grand Island, NY, USA). First-strand cDNA was synthesized using AMVRTase (Promega), and PCRs were performed. The Q-PCR forward and reverse primer sequences are as follows: for HIF- $1 \alpha, 5^{\prime}-$ GAAC GTCGAAAAGAAAAGTCTCG- $3^{\prime}$ and $5^{\prime}$-CCTTATCAAGATGCGAA CTCACA-3'; for $\beta$-actin, $5^{\prime}$-AAGGAAGGCTGGAAAAGAGC-3' and 5'-GCTACAGCTTCACCACCACA-3'

\section{PLD activity assay}

PLD activity was assessed by measuring the formation of $\left[{ }^{3} \mathrm{H}\right]$ phosphatidylbutanol, the product of PLD-mediated transphosphatidylation, in the presence of 1-butanol. Cells in 6-well plates were serum-starved overnight in the presence of $3 \mu \mathrm{Ci} \mathrm{ml}^{-1}\left[{ }^{3} \mathrm{H}\right]$ myristic acid. The cells were washed three times with phosphate-buffered saline and pre-equilibrated in serum-free Dulbecco's Modified Eagle's medium for $1 \mathrm{~h}$. For the final $10 \mathrm{~min}$ of preincubation, $0.3 \%$ 1-butanol was included. The extraction and characterization of lipids by thin-layer chromatography were performed as previously described. ${ }^{20}$

\section{In vitro $\mathrm{VHL}$ capture assay}

Biotinylated wild-type or proline-hydroxylated peptides (corresponding to HIF residues 556-574) were synthesized (American Peptide Company, Sunnyvale, CA, USA), dissolved in sterile water (500 $\mu \mathrm{g} \mathrm{ml}^{-1}$ ) and incubated with steptavidin beads (Pierce) at $4{ }^{\circ} \mathrm{C}$ for $2 \mathrm{~h}$. The beads were washed twice with VHL binding buffer $(20 \mathrm{~mm}$ Tris, $\mathrm{pH} 8,100 \mathrm{~mm} \mathrm{NaCl}, 1 \mathrm{~mm}$ EDTA, 0.5\% NP40) and three times with reaction buffer (20 mM Tris, $\mathrm{pH} 7.5,5 \mathrm{~mm} \mathrm{KCl,} 1.5 \mathrm{~mm} \mathrm{MgCl}_{2}$ ). For each condition, $2 \mu \mathrm{g}$ peptide $20 \mathrm{\mu l}^{-1}$ beads was aliquoted into separate tubes and the reaction buffer was added, along with cofactors $(100 \mu \mathrm{m}$ 2-ketoglutaric acid, $100 \mu \mathrm{M}$ L-ascorbic acid, $50 \mu \mathrm{m}$ ferrous chloride). The beads and HPH cofactors were mixed at room temperature for $15 \mathrm{~min}$ in reaction buffer. Prior to this incubation, PA was added to the appropriate tubes. Separate in vitro translated reactions (Promega) were the source for the HPH protein and Flag-VHL protein. A $5 \mu \mathrm{l}$ aliquot of in vitro translated HPH-2 was added to the bead-peptide mixture for $1 \mathrm{~h}$ at $30^{\circ} \mathrm{C}$. Subsequently, the beads were washed with VHL binding buffer and $10 \mu \mathrm{l}$ in vitro translated Flag-VHL was added to the beads overnight at $4{ }^{\circ} \mathrm{C}$. The beads were washed, SDS Laemmli buffer was added, the samples were boiled, subjected to sodium dodecyl sulfate-polyacrylamide gel electrophoresis, and resultant blots were probed for Flag.

\section{VEGF analysis}

The cell culture media of vector- and PLD-transfected cells were replaced with serum-free media 8 or $10 \mathrm{~h}$ before analysis of VEGF. The secreted VEGF was detected in the cell culture media by an ELISA kit (R\&D Systems). Each sample was harvested for quantification of protein, which was used to normalize VEGF levels. An experiment for each condition was carried out in triplicate.

\section{Data analysis}

Results were expressed as mean \pm standard error of the mean (s.e.m.). The statistical differences among the results of the various groups were compared by one-way analysis of variance followed by Tukey's (Honestly Significant Difference) test. A value of $P<0.05$ was considered significant. 
a

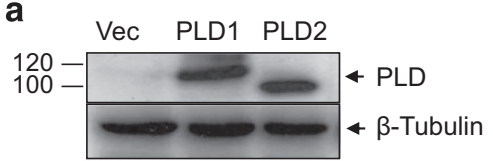

C

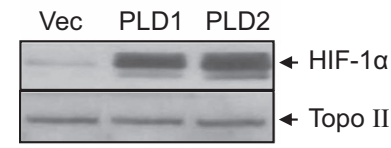

d

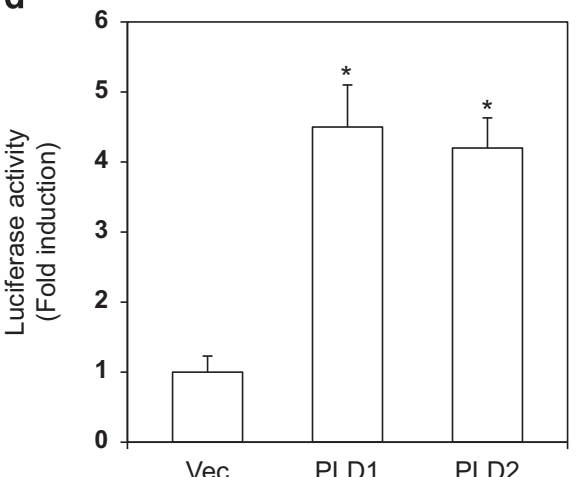

b

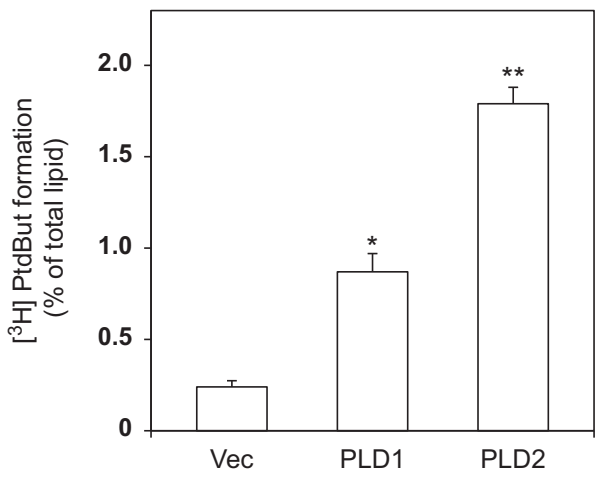

e

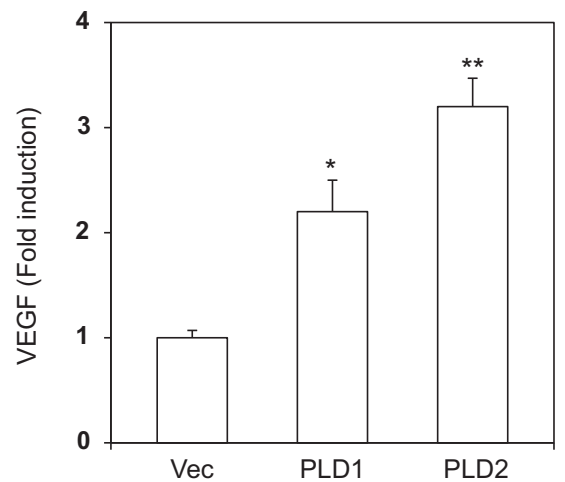

f
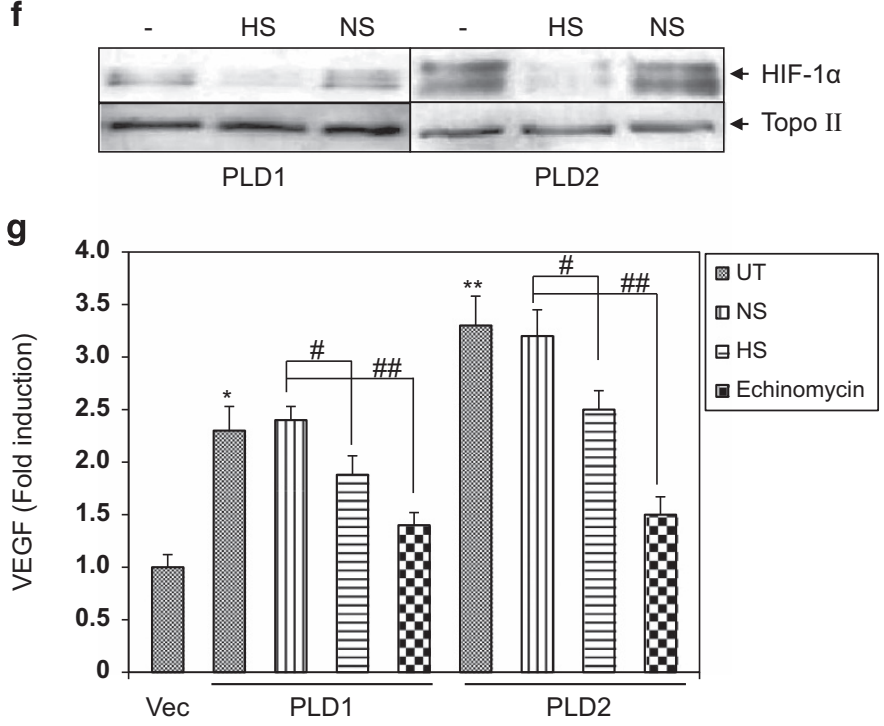

Figure 1 PLD activates the HIF-1-VEGF pathway. (a) Vector (Vec)- and PLD-transfected cells (PLD) were lysed to obtain whole cell lysates. PLD1 and PLD2 protein levels were monitored by western blot. (b) PLD activity in vector (Vec)- and PLD-transfected cells (PLD) was assessed as described in Materials and Methods. The data are means \pm s.e.m. $(n=3)$. ${ }^{*} P<0.01$ and ${ }^{* *} P<0.001$ vs Control (c) Vector (Vec)- and PLD-transfected cells (PLD) were lysed to obtain nuclear extracts and HIF-1 $\alpha$ protein was immunodetected by western blot. (d) Vector (Vec)- and PLD-transfected cells (PLD) were transfected with a HIF-1-dependent luciferase reporter plasmid and the luciferase activities were measure $10 \mathrm{~h}$ after the transfection. The data are means \pm s.e.m. $(n=4) .{ }^{*} P<0.01$ vs Control (e) Cell culture media of vector (Vec)- and PLD-transfected cells (PLD) were replaced with serum-free media $8 \mathrm{~h}$ before analysis of VEGF. Secreted VEGF was detected in the cell culture media by an ELISA kit. The data are means \pm S.e.m. $(n=3)$. ${ }^{*} P<0.05$ and ${ }^{* *} P<0.01$ vs Control (f) SiRNA specific for HIF-1 $\alpha$ (HIF-1 $\alpha$ siRNA, HS, $200 \mathrm{nmol}^{-1}$ ) was transfected in PLD-transfected cells. A nontargeting siRNA (NS) was used as a nonspecific control. One day post transfection, HIF-1 $\alpha$ in nuclear extracts was analyzed by western blot. (g) One day post transfection with HIF-1 $\alpha$ siRNA (HS) or non-targeting siRNA (NS) in PLD-transfected cells, cell culture media were replaced with serum-free media $8 \mathrm{~h}$ before analysis of VEGF. PLD-transfected cells were treated with echinomycin ( $20 \mathrm{~nm})$ for $8 \mathrm{~h}$ following replacement of cell culture media. Secreted VEGF was detected in the cell culture media by an ELISA kit. The data are means \pm s.e.m. $(n=3)$. ${ }^{*} P<0.05$ and ${ }^{* *} P<0.01$ vs Control, ${ }^{\#} P<0.05$ and ${ }^{\#} P<0.01$. 


\section{RESULTS}

\section{PLD activates HIF-1-VEGF pathway}

To examine the involvement of HIF-1 in PLD-mediated oncogenesis, human glioma cells stably transfected with PLD1, PLD2 or empty vector were prepared and expression of PLD1 and PLD2 was monitored. As shown in Figure 1a, PLD1 and PLD2 were expressed abundantly in the PLDtransfected glioma cells, whereas barely detected in the vector-transfected cells. To ensure that transfected PLD was functional, the metabolic product of PLD, PA, was measured. As shown in Figure 1b, a greater level of PA was detected in PLD-transfected cells than in vector-transfected cells.

We then examined whether PLD could lead to induction of HIF-1 $\alpha$ protein. PLD1, PLD2 and vector-transfected cells were lysed to obtain nuclear extracts and the levels of HIF- $1 \alpha$ protein were detected by western blot. As shown in Figure 1c, the levels of HIF-1 $\alpha$ protein were elevated in PLD-transfected cells compared with vector-transfected cells and HIF- $1 \alpha$ induction by PLD1 was comparable with that by PLD2. To examine whether PLD-induced HIF- $1 \alpha$ was transcriptionally active, the cells were transfected with a HIF-1-dependent luciferase reporter plasmid and the luciferase activities were measured. As shown in Figure 1d, the luciferase activities were greater in PLD-transfected cells than in vector-transfected cells and PLD1 showed a comparable ability to induce the luciferase with PLD2, which paralleled with the result of PLD induction of HIF- $1 \alpha$ protein.

To further confirm the transcriptional activity of PLDinduced HIF- $1 \alpha$, the secretion of VEGF, a target gene product of HIF-1 involved in tumor angiogenesis, was monitored in
PLD and vector-transfected cells. To do this, we determined the VEGF levels in the cell culture supernatants using an ELISA kit. As shown in Figure 1e, the VEGF levels in cell culture media of PLD-transfected cells were greater than those of vector-transfected cells. We next examined whether the VEGF secretion was dependent on HIF-1. PLD-transfected cells were treated with a specific biological (HIF-1 $\alpha$ siRNA, HS) or a chemical inhibitor of HIF-1 (echinomycin), and the levels of secreted VEGF were measured. As shown in Figure 1f, HIF-1 $\alpha$ siRNA but not scrambled siRNA (NS) attenuated HIF-1 $\alpha$ protein expression in PLD-transfected cells. Consistent with this observation, the VEGF secretion in PLD-transfected cells was attenuated significantly by HIF- $1 \alpha$ siRNA but not scrambled siRNA (NS). Echinomycin reduced VEGF levels as well (Figure 1g).

\section{PLD induction of HIF-1 $\alpha$ is mediated by the metabolic product of the enzyme, $P A$}

As PLD acts as a signaling amplifier by producing a lipid second messenger, PA, from PC, we examined whether PA was involved in PLD induction of HIF-1 $\alpha$ protein. PLD-transfected cells were treated with 1-butanol, which blocks generation of PA by PLD, and the same experiment was done with a negative control, 2-butanol. HIF-1 $\alpha$ levels were monitored in the nuclear extracts. As shown in Figure 2a, 1-butanol but not 2-butanol attenuated HIF-1 $\alpha$ induction in PLD-transfected cells. To verify this result, vector-transfected cells were treated with a cell-permeable PA (1, 2-dioctanoyl-sn-glycerol 3-phosphate sodium salt), and HIF- $1 \alpha$ protein was detected in the nuclear extracts. As shown in Figure 2b, the cell-permeable PA induced
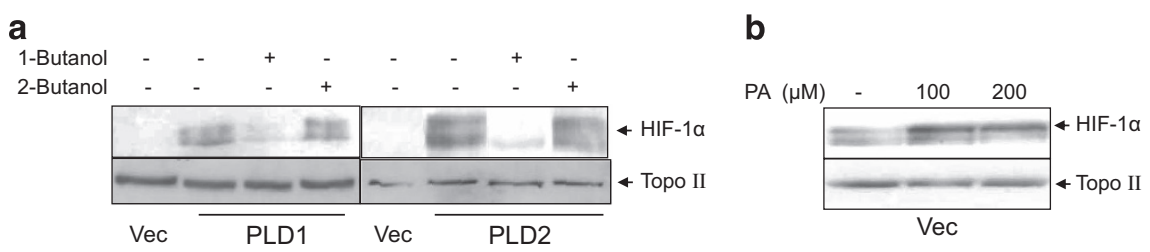

c

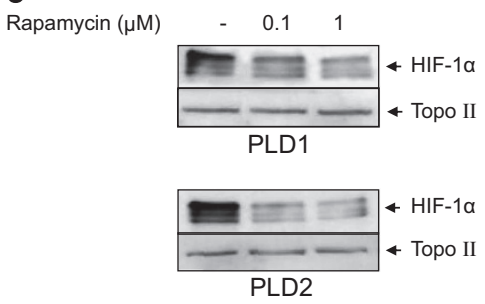

d

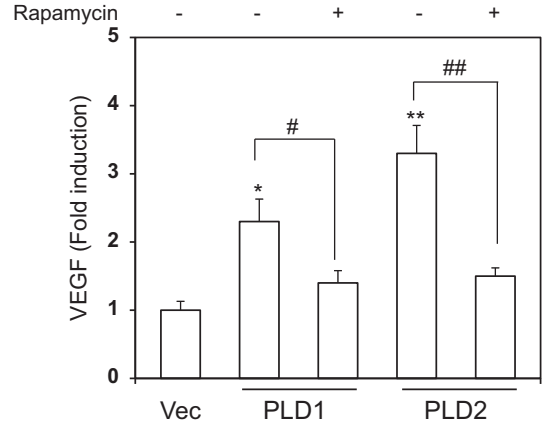

Figure 2 PLD induction of HIF-1 $\alpha$ is mediated by the metabolic product of the enzyme, PA. (a) PLD-transfected cells (PLD) were treated with 1 -butanol $(0.5 \%)$ for $4 \mathrm{~h}$ or with a negative control, 2-butanol $(0.5 \%)$. HIF-1 $\alpha$ protein was monitored in nuclear extracts by western blot. (b) Vector-transfected cells $(\mathrm{Vec})$ were treated with cell-permeable PA (PA) for $1 \mathrm{~h}$, and HIF-1 $\alpha$ protein was detected in nuclear extracts by western blot. (c) PLD-transfected cells were treated with rapamycin for $4 \mathrm{~h}$, and HIF-1 $\alpha$ protein was monitored in nuclear extracts by western blot. (d) PLD-transfected cells were treated with rapamycin $(1 \mu \mathrm{m})$ for $10 \mathrm{~h}$ following replacement with serum-free media, and the cell culture media were subjected to analysis of VEGF. The data are means \pm s.e.m. $(n=3)$. ${ }^{*} P<0.05$ and ${ }^{* *} P<0.01$ vs Control, ${ }^{\#} P<0.05$ and ${ }^{\#} P<0.01$. 
HIF-1 $\alpha$ protein. Via PA, PLD transmits numerous mitogenic signals to mTOR that regulates a wide range of cellular functions including cell proliferation and survival. ${ }^{21}$ We considered whether PLD activation of HIF-1-VEGF pathway involved mTOR activation. PLD-transfected cells were treated with rapamycin, an mTOR inhibitor, and the nuclear levels of HIF- $1 \alpha$ protein and secretion of VEGF were monitored. As shown in Figures $2 \mathrm{c}$ and $\mathrm{d}$, rapamycin substantially reduced nuclear HIF- $1 \alpha$ and VEGF secretion.

\section{PA does not affect $\mathrm{HPH}$ activity}

PLD upregulates HIF- $1 \alpha$ expression by accelerating HIF- $1 \alpha$ protein translation. ${ }^{22}$ To rule out the possibility of transcriptional regulation, PLD- and vector-transfected cells were subjected to PCR analysis. As shown in Figure 3a, no change in the levels of HIF-1 $\alpha$ mRNA was observed. We examined the possibility that PLD induction of HIF- $1 \alpha$ involved VHL and $\mathrm{HPH}$, the central components for the posttranslational regulation of HIF- $1 \alpha .^{23}$ To examine the effect of PA on HPH, the enzymes for HIF-1 $\alpha$ hydroxylation leading to VHL-dependent HIF- $1 \alpha$ degradation, ${ }^{23}$ an in vitro VHL capture assay was performed using a biotinylated HIF peptide that contains a conserved proline residue subject to $\mathrm{HPH}$-dependent

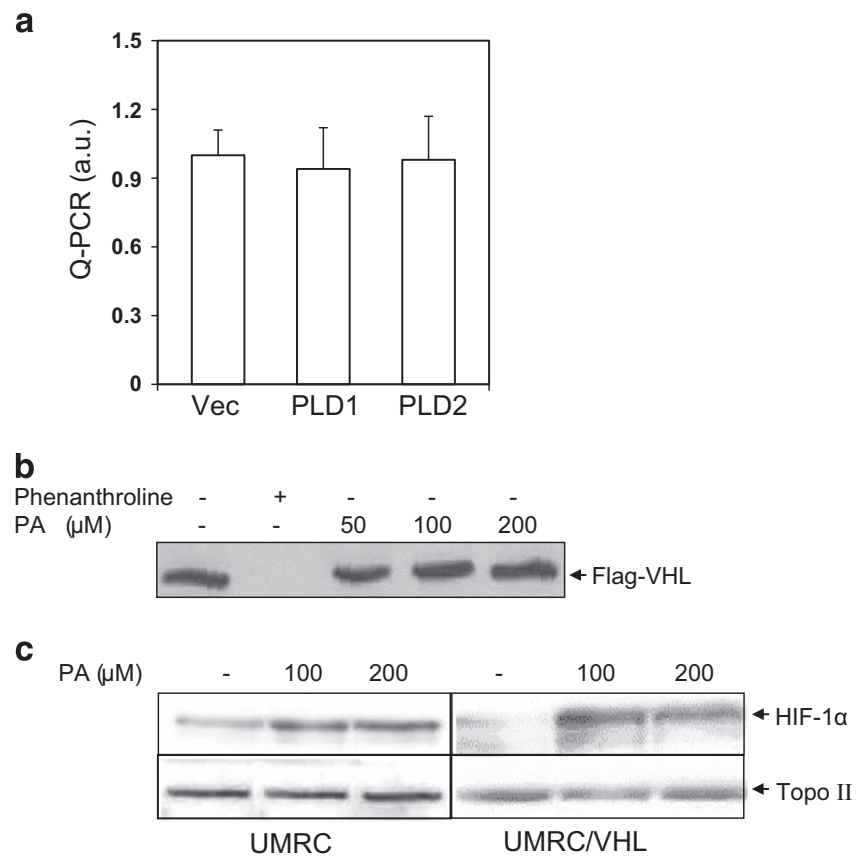

Figure 3 PA does not affect HPH activity. (a) Total RNA in vector (Vec)- and PLD-transfected cells (PLD) was isolated by the TRIzol reagent and was subjected to Q-PCR for analysis of HIF-1 $\alpha$ mRNA. (b) A VHL capture assay using biotinylated HIF peptide was performed as described under Materials and methods. The assay was performed in the presence of the indicated concentrations of PA and resultant blots were probed for FLAG (VHL). Phenanthroline $(100 \mu \mathrm{M})$, an iron chelator, was used as a positive control. (c) Renal carcinoma cells that are deficient for $\mathrm{VHL}$ function (UMRC2) or a clonally selected line with stably expressing VHL (UMRC2/VHL) were treated with PA for $1 \mathrm{~h}$ and $\mathrm{HIF}-1 \alpha$ protein was detected in nuclear extracts. hydroxylation. The hydroxylation reaction using in vitro translated HPH and the HIF peptide proceeded in the presence of $\mathrm{PA}$ and the hydroxylated HIF-peptide (OH-HIF peptide) was determined by binding of flag-tagged VHL to OH-HIF peptide. An iron chelator, phenanthroline, was used as the positive control. As shown in Figure 3b, PA did not affect VHL binding to the HIF peptide up to $200 \mu \mathrm{M}$, whereas the binding was completely prevented by phenanthroline, indicating that PA did not inhibit the enzyme activity directly. To test this observation in cells, both the parental VHL-deficient renal carcinoma cell line UMRC2 and UMRC2/VHL cells (stably transfected with VHL) were treated with PA, and HIF- $1 \alpha$ induction was compared in both cell lines. As HIF hydroxylation is required for VHL-dependent HIF- $1 \alpha$ ubiquitination and degradation, PA induction of HIF- $1 \alpha$ should occur independent of VHL status. As shown in Figure $3 c$, in parallel with the PA effect on HPH, PA increased HIF- $1 \alpha$ protein in UMRC2/ VHL as well as in parental UMRC2.

\section{PLD inhibition abolishes EGF induction of HIF-1 $\alpha$ and secretion of VEGF}

The above data were obtained in an artificial condition in which PLD was overexpressed. We wanted to examine whether the HIF-1-VEGF pathway would be modulated in a PLDdependent manner under a physiologic state. EGF activates oncogenic signals involved in the development of many types of cancers. ${ }^{24,25}$ We first tested whether EGF activated PLD in human glioma cells. As shown in Figure 4a, EGF activated PLD resulting in the increased generation of PA. We examined whether EGF-activated PLD led to HIF-1 $\alpha$ induction and VEGF secretion. Cells were treated with EGF in the presence of a pan PLD inhibitor and VEGF secretion and HIF- $1 \alpha$ induction were monitored. As shown in Figures $4 \mathrm{~b}$ and c, EGF increased the cellular level of HIF- $1 \alpha$ and VEGF secretion, which were abolished by the specific PLD inhibitor.

\section{DISCUSSION}

In this study, we demonstrated that stable transfection with PLD (PLD1 and PLD2) in glioma cells elevated the level of HIF- $1 \alpha$ protein via the metabolic product of the enzyme, PA. PLD induction of HIF- $1 \alpha$ led to VEGF secretion. Moreover, PLD activated by EGF resulted in HIF- $1 \alpha$ induction and VEGF secretion. Our data suggest that PLD utilizes HIF-1-VEGF pathway as a tumorigenic effector.

PLD is involved in maintaining HIF-1 $\alpha$ level in VHLdeficient renal carcinoma cells. ${ }^{22}$ PLD likely elevates HIF- $1 \alpha$ level in cells with functional VHL as shown by the data demonstrating that HIF- $1 \alpha$ increased in glioma cells transfected with PLD. However, in parallel with a previous paper demonstrating that PLD induction of HIF- $1 \alpha$ is controlled by the translational rate of HIF- $1 \alpha,{ }^{22}$ PLD induction of HIF- $1 \alpha$ did not involve transcription of HIF-1 $\alpha$ mRNA as PLD overexpression did not change HIF-1 $\alpha$ mRNA level. In addition, posttranslational stabilization of HIF-1 $\alpha$ does not have a significant role in PLD induction of HIF-1 $\alpha$. Our data showed that PA, which is thought to be a major effector for 

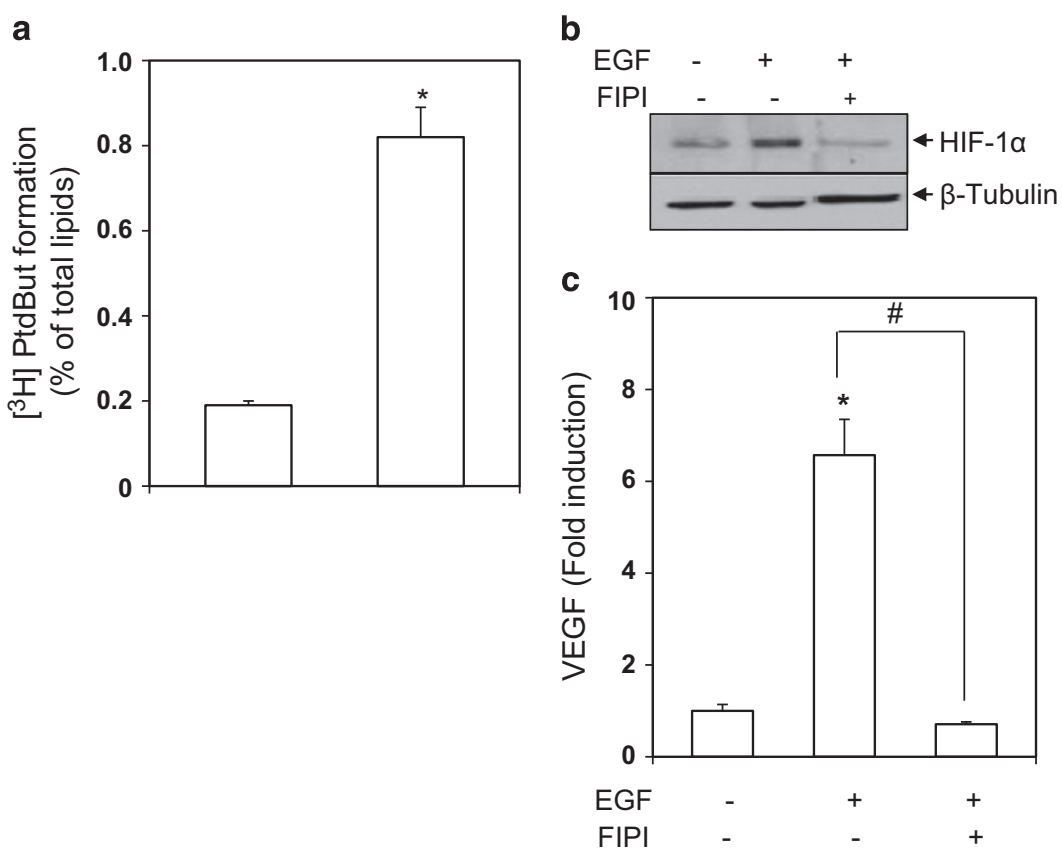

Figure 4 PLD inhibition abolishes EGF induction of HIF- $1 \alpha$ and secretion of VEGF. (a) Human glioma U87 cells were labeled with I [ $\left.{ }^{3} \mathrm{H}\right]$ myristic acid overnight, and then treated with EGF (100 nM) for $1 \mathrm{~h}$ in the presence of $0.3 \% 1$-butanol. $\left[{ }^{3} \mathrm{H}\right]$ Phosphatidylbutanol was measured as described in Materials and Methods. The data are means \pm s.e.m. $(n=3)$. ${ }^{*} P<0.001$ vs Control (b) Cells were pretreated with a pan PLD inhibitor, 5-fluoro-2-indolyl des-chlorohalopemide (FIPI, $1 \mu \mathrm{m}$ ) for $30 \mathrm{~min}$ followed by stimulation with EGF (100 nm) for $4 \mathrm{~h}$. The whole cell lysates were immunoblotted to detect HIF-1 $\alpha$. (c) Cells were pretreated with FIPI ( $1 \mu \mathrm{m})$ for 30 min followed by stimulation with EGF (100 nm) for $20 \mathrm{~h}$. Secretion of VEGF was quantified by ELISA. The data are means \pm s.e.m. $(n=3)$. ${ }^{*} P<0.001$ vs Control, and $\# P<0.001$.

PLD-mediated HIF-1 $\alpha$ induction as discussed below, did not inhibit HPH in in vitro VHL capture assays and was able to induce HIF- $1 \alpha$ regardless of VHL status of cells. The HPHVHL pathway is the central posttranslational mechanism for regulating HIF- $1 \alpha$ protein stability. ${ }^{23}$

PLD induction of HIF- $1 \alpha$ is suggested to be mediated by PA, the metabolic product of PLD. This argument is supported by the data showing that 1-butanol, a PA generation inhibitor, reduced HIF- $1 \alpha$ protein level in the PLD-transfected cells. Involvement of PA in PLD-mediated HIF- $1 \alpha$ increase was further confirmed by the data showing that PA per se elevated the HIF-1 $\alpha$ level in vector-transfected cells.

PA acts as a second messenger to mediate PLD signals to downstream signaling molecules including mTOR., ${ }^{6,26}$ Our data suggest that PA generated by PLD utilizes the MTOR pathway to induce HIF-1 $\alpha$. Rapamycin, an mTOR inhibitor, reduced HIF-1 $\alpha$ protein level in the PLD-transfected cells. This observation may not be surprising considering that mTOR is known to regulate the synthesis rate of HIF- $1 \alpha$ protein. ${ }^{27}$

PLD promotes the secretion of VEGF, a target gene product of HIF-1. HIF-1 dependency on PLD-mediated VEGF secretion was demonstrated in an experiment using specific HIF-1 $\alpha$ inhibitors. These findings indicate that PLD can activate HIF1-VEGF pathway. However, we do not rule out the possible involvement of HIF-2 in PLD-mediated VEGF secretion because PLD is able to induce HIF- $2 \alpha^{22}$ and HIF- $1 \alpha$ siRNA does not suppress PLD secretion of VEGF by more than 50\% although HIF-1 siRNA markedly reduced HIF-1 $\alpha$ levels in PLD-transfected cells

Our findings in PLD-overexpressed conditions are validated in experiments using an oncogenic/mitogenic stimulus that activates PLD. In glioma cells stimulated with EGF, PLD was activated. EGF induced HIF- $1 \alpha$ and promoted the secretion of VEGF. Consistent with the results obtained from PLDoverexpressed cells, PLD inhibitors abolished the EGFmediated effects on HIF- $1 \alpha$ and VEGF. Actually, many oncogenic and mitogenic stimuli that activate PLD are able to induce HIF-1 $\alpha$ via signaling pathways in which mTOR participates. ${ }^{16,17}$ It should be intriguing to investigate whether such induction of HIF- $1 \alpha$ involves PLD.

Taken together, these data demonstrate that PLD upregulates functional HIF- $1 \alpha$ protein through a PLD signaling pathway involving PA and mTOR, culminating in the secretion of VEGF, a strong angiogenic factor required for tumor growth and metastasis. Thus, PLD may utilize HIF-1-VEGF pathway as a tumorigenic effector.

\section{CONFLICT OF INTEREST}

The authors declare no conflict of interest.

\section{ACKNOWLEDGEMENTS}

This work was supported by the Convergence Research Grant funded by the Pusan National University (PNU, Convergence Research Grant, PNU-2012-0094-0001). 
1 Exton JH. Regulation of phospholipase D. Biochim Biophys Acta 1999; 1439: 121-133.

2 Zaremberg V, McMaster CR. Differential partitioning of lipids metabolized by separate yeast glycerol-3-phosphate acyltransferases reveals that phospholipase $D$ generation of phosphatidic acid mediates sensitivity to cholinecontaining lysolipids and drugs. J Biol Chem 2002; 277: 39035-39044.

3 Kang DW, Choi KY, Min do S. Phospholipase D meets Wnt signaling: a new target for cancer therapy. Cancer Res 2011; 71: 293-297.

4 Gomez-Cambronero J. Phosphatidic acid, phospholipase D and tumorigenesis. Adv Biol Regul 2014; 54: 197-206.

5 Fang Y, Vilella-Bach M, Bachmann R, Flanigan A, Chen J. Phosphatidic acid-mediated mitogenic activation of mTOR signaling. Science 2001; 294: 1942-1945.

6 Ktistakis NT, Delon C, Manifava M, Wood E, Ganley I, Sugars JM. Phospholipase D1 and potential targets of its hydrolysis product, phosphatidic acid. Biochem Soc Trans 2003; 31: 94-97.

7 Foster DA. Regulation of mTOR by phosphatidic acid? Cancer Res 2007; 67: 1-4.

8 Zheng Y, Rodrik V, Toschi A, Shi M, Hui L, Shen Y et al. Phospholipase D couples survival and migration signals in stress response of human cancer cells. J Biol Chem 2006; 281: 15862-15868.

9 Shi M, Zheng Y, Garcia A, Xu L, Foster DA. Phospholipase D provides a survival signal in human cancer cells with activated H-Ras or K-Ras. Cancer Lett 2007; 258: 268-275.

10 Salceda S, Caro J. Hypoxia-inducible factor 1alpha (HIF-1alpha) protein is rapidly degraded by the ubiquitin-proteasome system under normoxic conditions. Its stabilization by hypoxia depends on redox-induced changes. J Biol Chem 1997; 272: 22642-22647.

11 Semenza GL. Hypoxia-inducible factor 1 (HIF-1) pathway. Sci STKE 2007; 2007: $\mathrm{cm} 8$.

12 Fandrey J. Erythropoiesis-once more HIF!. Blood 2008; 112: 931-932.

$13 \mathrm{Li}$ QF, Dai AG. Hypoxia inducible factor-1 alpha correlates the expression of heme oxygenase 1 gene in pulmonary arteries of rat with hypoxia-induced pulmonary hypertension. Acta Biochim Biophys Sin (Shanghai) 2004; 36: 133-140.

14 Brune B, Zhou J. The role of nitric oxide (NO) in stability regulation of hypoxia inducible factor-1alpha (HIF-1alpha). Curr Med Chem 2003; 10: 845-855.

15 Choi KS, Bae MK, Jeong JW, Moon HE, Kim KW. Hypoxia-induced angiogenesis during carcinogenesis. J Biochem Mol Biol 2003; 36: 120-127.

16 Bardos JI, Ashcroft M. Hypoxia-inducible factor-1 and oncogenic signalling. Bioessays 2004; 26: 262-269.

17 Gomez-Cambronero J. New concepts in phospholipase D signaling in inflammation and cancer. ScientificWorldJournal 2010; 10: 1356-1369.
18 Park MH, Ahn BH, Hong YK, Min do S. Overexpression of phospholipase D enhances matrix metalloproteinase-2 expression and glioma cell invasion via protein kinase $\mathrm{C}$ and protein kinase A/NF-kappaB/Sp1-mediated signaling pathways. Carcinogenesis 2009; 30: 356-365.

19 Matsumoto Y. Base excision repair in mammalian cells. Methods Mol Biol 2006; 314: 365-375.

20 Kim J, Choi BH, Jang KL, Min DS. Phospholipase D activity is elevated in hepatitis $\mathrm{C}$ virus core protein-transformed NIH3T3 mouse fibroblast cells. Exp Mol Med 2004; 36: 454-460.

21 Asnaghi L, Bruno P, Priulla M, Nicolin A. mTOR: a protein kinase switching between life and death. Pharmacol Res 2004; 50: 545-549.

22 Toschi A, Edelstein J, Rockwell P, Ohh M, Foster DA. HIF alpha expression in VHL-deficient renal cancer cells is dependent on phospholipase D. Oncogene 2008; 27: 2746-2753.

23 Jaakkola P, Mole DR, Tian YM, Wilson MI, Gielbert J, Gaskell SJ et al. Targeting of HIF-alpha to the von Hippel-Lindau ubiquitylation complex by 02-regulated prolyl hydroxylation. Science 2001; 292: 468-472.

24 Lu Z, Hornia A, Joseph T, Sukezane T, Frankel P, Zhong M et al. Phospholipase $D$ and RalA cooperate with the epidermal growth factor receptor to transform 3Y1 rat fibroblasts. Mol Cell Biol 2000; 20: 462-467.

25 Lee CS, Kim KL, Jang JH, Choi YS, Suh PG, Ryu SH. The roles of phospholipase D in EGFR signaling. Biochim Biophys Acta 2009; 1791: 862-868.

26 Hornberger TA, Chu WK, Mak YW, Hsiung JW, Huang SA, Chien S. The role of phospholipase $\mathrm{D}$ and phosphatidic acid in the mechanical activation of mTOR signaling in skeletal muscle. Proc Natl Acad Sci USA 2006; 103: 4741-4746.

27 Cho D, Signoretti S, Regan M, Mier JW, Atkins MB. The role of mammalian target of rapamycin inhibitors in the treatment of advanced renal cancer. Clin Cancer Res 2007; 13: 758s-763s.

(c) (1) ()(2) This work is licensed under a Creative Commons (BY Na BA Attribution-NonCommercial-ShareAlike 3.0 Unported License. The images or other third party material in this article are included in the article's Creative Commons license, unless indicated otherwise in the credit line; if the material is not included under the Creative Commons license, users will need to obtain permission from the license holder to reproduce the material. To view a copy of this license, visit http:// creativecommons.org/licenses/by-nc-sa/3.0/ 